\title{
The Deep Industry-education Integration in the Practical Teaching of Environmental Design Specialty under the Background of Innovation
}

\author{
Yilin Zhou \\ Sichuan Normal University, Chengdu 610101, Sichuan, China \\ Email: 122050557@qq.com
}

\begin{abstract}
The industry-education integration is a characteristic of higher vocational colleges, and it is also the foundation and driving force of economic and industrial innovation and development. This article is based on Several Opinions on Deepening the Integration of Industry and Education, Vocational School School-Enterprise Cooperation Promotion Law and other documents. On the basis of analyzing and thinking about the feasibility and influencing factors of the deep industry-education integration in the practical teaching of environmental design specialty under the background of innovation, this paper explores how to maximize the effectiveness of the deep industry-education integration in the practical teaching of environmental design specialty.
\end{abstract}

Keywords: innovation background, environmental design specialty, practical teaching, deep industry-education integration

\section{Introduction}

After more than ten years of development in China's higher vocational education, certain achievements and experience have been obtained in the practical exploration of the industry-education integration. Especially after going through the talent training mode of "combination of learning with working" and the mode of school-enterprise cooperation, the industry-education integration in China's higher vocational education during the "13th Five-Year Plan" period has officially entered the exploratory stage of the "cross-system of production and education" "[1]. Based on this, the practical teaching of environmental design specialty under the background of the deep industry-education integration can actually try the teaching forms, contents and evaluation methods as well as the construction of executive power mechanism, guarantee mechanism, operation mechanism and evaluation mechanism according to the characteristics of professional teaching and the actual needs of students for entrepreneurship and employment. In this way, the resources of the school and the enterprise can be gathered from both theoretical and practical aspects to cultivate students' comprehensive literacy, vocational skills and job competence.

\section{The construction of the training mode of deep industry-education integration in environmental design specialty under the background of innovation}

\subsection{Theory and practice run in parallel to construct a "specialty + studio" training mode}

For a long time, the practical exploration of the mode of industry-education integration in higher vocational colleges has provided a good soil for the reform and innovation of environmental design specialty teaching. The industry-education integration in higher vocational colleges not only helps environmental design teachers standardize, design, innovate and practice teaching methods, and increase the benign interaction with students, but also helps teachers adjust their teaching concepts and focus on the frontier development trends of the environmental design specialty and enterprise needs ${ }^{[2]}$. In particular, the integration of the double-qualified teacher team in the teaching reform of the environmental design specialty has greatly improved the educational quality and talent output efficiency of the environmental design specialty.

However, under this teaching mode, the integration of the concept of industry-education integration, collaborative education and the teaching innovation of environmental design has not completely broken the shackles of disciplines. Whether according to the requirements of teaching innovation of environmental design specialty, or taking into account the market demand of environmental design professionals, it is imperative to continuously expand the width and breadth of subject teaching, decompose the teaching curriculum of environmental design specialty, and form a gradient teaching system. Therefore, from the perspective of maximizing mobilization of students' learning enthusiasm, teaching students in accordance with their aptitude, and developing students' potentials as needed, it is recommended that the teaching of environmental design specialty be under the mode of deep industry-education integration. Higher vocational colleges should employ well-known corporate executives and industry experts as guest professors of environmental design majors, 
and regularly hold classroom lectures for students of this specialty.

In order to expand the depth and breadth of the subject, the teaching content of art subjects and architecture subjects can also be considered. Integrate the teaching of environmental design specialty with lighting laboratory, model making training room, decoration material laboratory, interior decoration training room, etc. According to multiple modes such as project period discussion and theme analysis discussion ${ }^{[3]}$, combine theory and practice, and double deepen students' cognition and understanding of professional theoretical knowledge. In terms of practical innovation, the practical teaching of environmental design specialty can divide students into different groups according to their learning ability, and use the studio mode to increase the proportion of professional practical courses and practical links. The modes of team discussion and team research and exploration are conducive to students' mutual assistance and cooperation and learn from each other's strong points to make up for their weaknesses. Qualified higher vocational colleges can also use professional internships and other modes to focus on cultivating students' team awareness and hands-on ability. What students see, hear, feel, think, think, and gain in practice can be an aid for students to improve their job suitability and job competitiveness in school period.

\subsection{Give full play to the advantages of the dual-mentor system and build a "topic + project" training mode}

Judging from the effectiveness and experience of the industry-education integration in China's higher vocational colleges in recent years, the biggest advantage of the deep industry-education integration in practical teaching of environmental design is the possibility of having a double-qualified teacher team, and having double incubators of schools and enterprises ${ }^{[4]}$. Therefore, in the process of practice teaching innovation of environmental design specialty, combined with the requirements of the market for the innovation and development of this specialty and the targeted training of students, the school can employ industry experts to build a team of studio practice mentors according to different types of projects and the actual content of the requirements, and the professional teachers in the school can work with industry experts to set up a dual-tutor teaching community.

In school period, students can choose topics together with their mentors, which are mainly students and assisted by mentors, and research topics or projects in an unbounded, interdisciplinary and interdisciplinary way. Mentors can provide full guidance for students' design, practice, innovative projects and even entrepreneurship. According to the actual operational needs of students and mentors, schools need to provide them with practice, training, experimental environment and platform covering multi-industry chain and professional chain, which can carry out skills and technical training, and meet experimental professional standards. The construction of the double-tutor system is convenient to train comprehensive talents with strong comprehensive quality, high professional quality, rich knowledge and interdisciplinary, but also can effectively solve the problems of high scores and low post adaptation of students under the traditional teaching methods.

\subsection{Taking projects as an orientation, build a dual-line training mode of industry-university- research collaborative education}

In the context of innovation, the deep industry-education integration in the practical teaching of environmental design specialty can take the project as the basic guidance, decompose the teaching content, and make it modular. The subject can also be extracted from the actual operation process of the project and the dual exploration of theoretical and practical research can be carried on. Considering that the Internet technology can promote the deep industry-education integration in environmental design specialty, on the premise of giving full play to the advantages of regional resources and intercollegiate discipline research experience and achievements, environmental design majors in higher vocational colleges can construct an online teaching mode of industry-university-research cooperation according to the application status of intercollegiate cooperation mechanism.

In terms of online teaching mode, higher vocational colleges in the same area can research, explore and share relevant materials on the same topic, theme or project. The allocation of software and hardware resources in environmental design specialty in vocational colleges is different, and this difference in the allocation of software and hardware resources can be used as the basis for cooperation in joint research and education at school-level universities. In addition to online education with high-efficiency inter-school linkages, higher vocational colleges can communicate horizontally with cooperative companies, influential construction companies and design companies inside and outside the province, and use the advantages of the Internet to hire outstanding employees and experts from companies to provide online educational video courses for students majoring in environmental design ${ }^{[5]}$. Online teaching and offline teaching complement each 
other and promote each other. In terms of offline teaching mode, teachers of environmental design specialty in higher vocational colleges are required to stimulate students' enthusiasm for participation in teaching, contextual teaching, etc., so that offline teaching experiments and theoretical research results can become an important basis for information sharing and cooperative communication in online teaching.

\section{Application of the deep industry-education integration training mode in environmental design under the background of innovation}

\subsection{Construct a progressive curriculum system and promote practical teaching at different levels}

The teaching of environmental design specialty under the mode of deep industry-education integration can adopt a model teaching method, from shallow to deep, from surface to point, layer by layer. For example, in the first grade, the status quo of industry enterprise development and the status quo of large-scale professional development can be integrated, and corporate culture, industry culture, and industry status can be imported, focusing on the analysis of professional direction, content, and the pertinence of professional talent training to help students establish clear career development goals at the entrance stage. The professional cognition training courses set up on the first level are also to help freshmen have a basic understanding of future careers. Cognitive training for environmental design specialty can be undertaken by the employees of the school's cooperative enterprises or senior students, and the performance is to lead the freshmen to analyze the most influential environmental design companies in the industry and the employment conditions of the positions. Qualified schools can send students to visit cooperative enterprises to learn about their operation methods, etc.

The second layer can be set with practical courses. Teachers can make full use of the resources of the school's training room and use multimedia methods to implement situational teaching on the theoretical content of each module of the environmental design specialty to improve students' practical ability. This level can be implemented in the second and third grades. The focus of the theoretical course is on the basic theories and principles of environmental design. What students need to learn is thinking methods, project design and expression skills. In this stage, the deep industry-education integration can be gradually deepened. The method of "teachers and students going out and industry experts being invited in" is adopted to expand and deepen classroom learning, focusing on the implementation of the incentive mode of "curriculum + certificate" ${ }^{[1]}$ to pave the way for later students to design the project. When experts enter the classroom, they must pass on the most cutting-edge professional development trends and professional basic knowledge, and combine the actual situation of professional development to impart practical and valuable experience and skills. Teachers and students go out of the school to learn about the company and industry through the first classroom, the second classroom, etc., and students are encouraged to obtain skill certificates and participate in subject competitions. These can be used as a presentation of the deep industry-education integration at this level.

The courses of the third level, apprenticeship training courses, can be used to explain the core professional courses on the basis of the second level. After the completion of the relevant major courses, teachers or schools may require students to use short-term courses in winter and summer vacations for internship. Students can get real projects from companies or competition projects from industry associations during school and internship, and then cooperate with mentors to carry out project-oriented teaching practice of in-depth integration of production and education. Teachers of this school, firstline designers and experts of the enterprise can jointly guide students to explore the teaching practice of thematic design, budget course and material structure. Professional teachers' off-class studios and enterprises can be used as a platform for the transformation of students' learning achievements to test students' practical operation results.

\subsection{Implement evaluation standards of project inspection to enhance students' comprehensive ability in a multi-dimensional and three-dimensional way}

During the graduation internship stage, students will truly accept social tests to examine whether the knowledge and skills they have learned during school meet the needs of the enterprise ${ }^{[6]}$. From the perspective of improving students' professional literacy and professional competitiveness, the school can completely use the company's inspection of students' ability to fit the student's position during the graduation internship as the evaluation standard for students' academic work in school period. This standard is conducive to improving students' professional literacy, collaboration ability, communication ability, and professional cognition, and helping students to be fully prepared for employment skills and psychological preparation. This can be arranged in the last semester.

In specific practical operations, in addition to the traditional paper-based examination, the school can introduce the company's assessment of employee skills and knowledge into the assessment of professional courses. Assess and evaluate 
according to the students' design ability and comprehensive professionalism at different project stages. The content of the evaluation should include the students' ability in plan design, site survey, drawing expression, plan expression and display, teamwork and communication. In addition to school visits, students can also conduct self-assessment, and the two together account for one-half of the students' final grades.

The other half are students' graduation works. From the perspective of cultivating students' research ability in depth, the school can integrate the graduation defense with the cultivation of students' comprehensive ability, and provide students with graduation topics in the research and practice courses, or it is up to the students to choose their own topics and research based on the objective conditions of the internship unit and their thoughts in the internship. Research and practice courses are also practical training courses for students in the last academic year. Under the guidance of professional teachers, students can use professional skills, methods and theoretical knowledge they have learned to solve various problems in the internship through the writing of graduation thesis, which can lay the foundation for entering the society and getting to work.

\section{References}

[1] Xie Xuetian. The construction of a practical teaching training system that integrates production and education in environmental design majors. Art Education. 2020; (08): 252-255.

[2] Wang Di, Gan Lu. The construction of an excellent talent training model based on the "studio system" of the integration of industry and education. Housing and Real Estate. 2019; (33): 228.

[3] Jiao Lin. Exploration on the reform of practical teaching of environmental art design major in higher vocational education under the background of school-enterprise cooperation. Joint Journal of Tianjin Vocational Colleges. 2019; 21(12): 27-31.

[4] Yu Xiwen. Research on the assessment reform of school-enterprise cooperation courses for environmental design majors - Taking "Interior Decoration Materials and Construction Technology" as an example. Journal of Beijing Institute of Graphic Communication. 2020; 28(03): 146-149.

[5] Chu Haifeng. Research on the reform of environmental design talent training model in western local colleges and universities. Hunan Packaging. 2019; 34(02):113-115.

[6] Hu Li. (2016) Subject and environment: the balance of higher vocational education employment ecosystem. Ph.D. Thesis, Hunan Normal University, Changsha. 